\title{
A Tentative Expansion of Variation Theory: A Case Study on "One Belt and One Road"
}

\author{
Shunqing Cao*, Wenting Shi \\ Sichuan University, Chengdu, China \\ Email: *shunqingcao@163.com,450418764@qq.com
}

Received 27 March 2016; accepted 24 June 2016; published 27 June 2016

Copyright (C) 2016 by authors and Scientific Research Publishing Inc.

This work is licensed under the Creative Commons Attribution International License (CC BY). http://creativecommons.org/licenses/by/4.0/

c) (i) Open Access

\begin{abstract}
Misunderstanding and misinterpretation are common existence when an item of news is put to its global distribution. On the basis of Variation Theory of Comparative Literature (VTCL) proposed by Chinese scholar Cao Shunqing, the present paper makes a case study on various international news reports on "One Road, One Belt" initiated by Chinese government in 2015. The aim of this study is on one hand to reveal how misunderstanding and misinterpretation happen during its circulation, and to test the feasibility of VTCL in the research of Mass Media on the other. The significance of such investigation lies in the construction of a new path to the sought of difference between heterogeneous cultures and further attempt to build up variation theory of communication.
\end{abstract}

\section{Keywords}

Journalism and Communication, Variation Theory, One Belt and One Road

\section{Introduction}

Variation Theory of comparative literature is a new sight of comparative literature research. It combines several concepts and theories which present multiple perspectives on literature, translation and cross-culture. The significance of Cao's book, Variation Theory of Comparative Literature, should be recognized as Fokkema points out in this book's Foreword, “Cao's book aims to open a dialogue with scholars abroad, in Europe, North and South America, India, Russia, South Africa, and the Arab world” (Fokkema, 2013). In the past, Chinese scholars always tried to seek homogeneity, but now we will try to seek heterogeneity, not only in comparative literature, but also in communication study.

When Variation Theory applied on communication, it may more cross over to cross-culture study, directly

\footnotetext{
*Corresponding author.
} 
focusing on the variations of message interpretation and communication activity message when across different culture, probing for the cultural motivation behind it.

This prompts two lines of inquire: Given that communication involves several types of crossover, what variations happens during the process? How does it happen? That is probing the deeper cultural motivation behind it. Seeking the difference from the sameness brings the possibility of understanding, blending, and communication in this multi-culture atmosphere.

Some basic claims about VTCL are presented first. A second set of arguments concerns the possible variations during communication, the relativity of communications studies and literature, and the feasibility of redefining communication studies from the view of variations. The following part is analysis on specific case: China's Belt and Road Initiative. Last, I conclude with possible function and features. This reveals how one culture misunderstands the other culture, afterward is probably changed and functioned by it —in other words, the importance of focusing on variation.

\section{Variation Theory of Comparative Literature}

Broadly speaking, Variation Theory of comparative literature is a new breakthrough of comparative literature. Comparative literature used to mainly focus on interactions between literature and other arts forms, or among two or over two kinds of national literature. It have been successfully going through two stages: Influence Study and Analogy Study, the previous of which is positivism on the longitudinal influence of the literary works, while the latter one the horizontal commonality by the unaffected different literatures, both of which are the western paradigms. However, with the blending of multi-culture and the increase in the input/output activity of global culture, a growing number of oriental cultural elements find their way into western countries' films, televisions, literatures, and art creation works. For example, the works of western culture worlds gradually increases the weight of Chinese culture. The Chinese images in them are also becoming to stand on the positive side. At the most start in 2020s, with the "yellow peril” fear prevailing in western worlds, the United States used few parts of Chinese elements and always the evil spirit. Dr. Fu Manchu was invented as a demonized Chinese character in several series of works at that time; to 2060s, Li xiaolong has become a positive Chinese image in Hollywood works; Until now, the Hollywood movies gradually set China as the main story background (such as Mission Impossible 5, Turandot runs throughout the whole movie; Also, the view is from Xitang Ancient Town, Zhejiang, China), or even set China's help as turning point (China provides NASA with critical assistance in The Martian).

The newly emerging phenomena need new theories to explain. Many scholars find although the oriental civilization has different foundation from the western civilization, the works communication between them creates a new possibility: the conflict and integration among eastern and western cultures, or different literary traditions.

Thus, after oriental civilization intervening the western circles, the influence studies and the analogy studies, which prevailed in the US and Europe previously, becomes far from complete. Lots of works mention, involve, even highlight variation(or "heterogeneity”, "heterology”) and presented it, for example, as new stage of EastWest culture communication by Yue daiyun (Yue, 1994), as an important idea to stand against the so-called universality of Western thoughts by François Jullien (Qin, 1996). Even though there are differences between their definition or interpretation of their theory, they share certain unifying themes: 1) the existing West frame work of comparative literature has little room for theoretical innovations; 2) the "heterogeneity" must replace the "sameness" as the core of comparison; 3) Eastern Culture will be new party to distort, edit, or redefine the content of comparative literature.

In the theoretical framework of original western comparative literature, the comparison of eastern and western civilizations is suspected. For example, Weinstein (1973), the famous American comparatist, claims that literature comparison between different civilizations is not feasible and comparable. However, the research method that always pays attention to the similarities drags the comparative literature discipline into a dead end. Based on the solid foundation of all researches (like Weisstein, 1973; Said, 1983; Yue \& Le, 1995; Xie, 1999; Yan, 2000, and so on) on heterogeneity an all-round elaboration of a new theory is given in The Variation Theory of Comparative Literature (2013), in hoping to overcome the "sameness" pitfall and breakthrough the western theoretical bond of comparative literature. The new theory advocates exploring the inherent law of literature by studying the variation condition of literary exchange between different countries and different civilizations.

While it was once considered incomparable because the comparison must be on the same basis, this kind of 
variation based on the notion of incommensurability between eastern and western literatures is actually can be compared. If the focus sustained on the similarities, it will become a shallow analogy. Comparative literature has been trapped in the superficial “ $x+y$ ” analogies. By my rough statistics, among 97 papers on the similarities between Li Bai and Romanticism, only 8 of them break the stereotype, looking for a different kind of perspective of Romanticism. This results from the western theoretical framework blindly seeking similarities (I mentioned it in the other works. Please refer to it if you are interested). Only after the deep variation under the surface of similarities is probed, can more profound understanding of the emergence and characteristics of the similarities be obtained. Therefore, it is necessary to find the similarities between the object of study, and then further study variability, and interpret the differences and the reasons behind them.

As variations may happen among different languages, cultures, and civilizations, several claims about heterogeneity are classified into four types of variations: Cross-national variation, interlingual variation, intercultural variation and cross-civilization variation.

First of all, the outcome of the comparing the variability behind similarities is the Domestic Appropriation of literature, namely the deep variation after a country's literature spreading to other countries through translation, cultural filtering and acceptation. There are two research directions: firstly, after the heterogeneous culture enters a country, indigenization will happen. The comparison of the similar concepts, phenomenon and the cultural differences behind the opinion sat the same time can help to retain the native culture under the influence of cultural diversity. China's construction and pursuit of its academic theories at current stage are as such. When the Oriental countries were obliged to enter their modernizing process (like Meiji Reform in Japan and the New Culture Movement in 1919), western political and cultural ideologies were perceived and then absorbed as advanced notions for the practical sake of the acceleration the very process. Therefore, a problematic situation has taken its shape gradually: with the influx of Western concepts in China, the western paradigm has now become the seemingly standardized global academic concept. As a result, some young Chinese generations lost the track of traditional Chinese culture. With engraving, calligraphy, Sinology, Kongfu, Beijing opera pushed to the edge of the mainstream, Chinese traditional discourse is silenced by the western discourses.

Secondly, when one culture enters other countries, the domestic appropriation will happen. For instance, Introduced from Russia to China in Lenin era, the Orthodox Marxism once became the guiding ideology of the Communist Party of China. Even with its Russian origin, it was altered to some extent. By tracing the transmission route of this, the assimilation and dissimilation can be understood only on the surface. Therefore, China is incorporating Western Marxism or New Marxism in an attempt to restore a Marxist tradition of whole picture and tailor Marxism to China’s current needs (Chen, 2005; Zhang, 2016; Chen, 2015; Zheng, 2013).

Generally speaking, Variation methodologies will help us distinguish all the superficial culture affinities which pertain to distinct underlying culture roots. Variation Theory of comparative literature is an attempt to enlarge the long-running framework of comparative literature in the West in which little room is left for comparisons of works between different civilizations. Variation methodologies not only focus on comparative literature, but also more on Eastern and Western culture`s similarities, variations, understandings or convergence. Within the framework of cross-cultural communication, the relentless search for similarities is certainly arbitrary thinking; the equal dialogue can be reached under the premise of mutual respect, taking culture diversities into consideration and keeping their respective national spirits intact.

\section{Variation Theory and Communication}

Due to communication activity's multidisciplinary features, the research on it surely bears the same characteristics and only thrives on other disciplines. Take the Journalism communication studies as examples, According to the statistics, the Chinese mainland doctoral dissertations cover over 23 disciplines, of which the highest frequencies are management science and historiography (Wu, 2014).

For China's communication study, however, the symbiosis of new literature and news brought by Vernacular Movement in May 4th movement in Modern times proves that the communication is bound to connect with literature and art in China. However, a big debate in the field of communication studies in China is whether communication theories need localization. Many scholars (Li, 2013; Liu, 2011; Hu, 2011) think the western communication theories, getting involved in the academic system in China since the 1920s, are not suitable for China's current national conditions. They seek to summarize the communication theory and discuss the possibility of localization, while some object it (Chen, 2002). With the advent of “consumer society” and “new media so- 
ciety”, the prior theory of literary studies was not able to account for the new problems surged from the literary production and distribution processes. Thus, contextual and co-textual differences should not be ignored. After the production and consumption of literature and art turn to the era of electronic media and era of digital copy from the era of mechanical reproduction, the focus of the problems starts to turn to consumption-centered theory from productivity-centered theory. The connection of literature and art and media has become historical necessity. He Zhijun (2012) proposes the viewpoint that the connection of literature and art and media has become historical necessity from the perspective of production and consumption of literature and art. Thus, it becomes possible for the communication to refer to the literary and art theory, and literary theory.

In many literary theories, I try to reinterpret communication from the perspective of variation studies. Communication involves multicultural and multidisciplinary study. Medium not only conveys the information, but also involves cultural factors behind it. With the prevalence of multiculturalism, subordinate cultures may adapt a non-cooperational strategy in order to shun the control of dominant culture. To achieve its own cultural dominance in the international surrounding, it must avoid the other that has been subjectified, that is to say to understand the other from its own perspectives with its own symbols, concepts or language, and also commit to controlling the other. There is an inevitable variation in the process. Thus, to interpret communication with variation studies becomes a possibility.

In addition, the process of modern communication expands the territory of its influence on one hand, while undermining its connotation on the other. Messages are often than not sent out in more entertaining and simple way for the recipients to be attracted, remember and pass on instantaneously, words becomes more catchy and plain, therefore easy enough to circulate in the media arena. This sustained transmitting action would gradually lead to the popularity and normalization of the Internet phrase, then the reduction and simplification of the connotation it is originally meant to be. For example, due to the popularity of Japan, South Korea and Western Entertainment culture, the user viscosity of the Internet pushes the network languages with popularity and playfulness spreading at a rapid speed on the Internet, even coined in daily face-to-face dialog. Now, we use "WTF" to express our outrage, borrowed from numbers of popular US TV series; use “大丈夫” to show concerns about someone, borrowed from common phrase “大丈夫 (だいじょうぶ)” in Japanese anime (Japanese borrows some Chinese characters to form their languages, so some of Japanese words are completely same in characters but different in pronunciation); “欧巴” is used as a term of address a young male who is adorable for younger girls, borrowed the meaning and pronunciation from the Korean word “오빠”. The expressions combined by the Chinese and foreign culture becomes prevalent among the youth subculture-whether it has enriched the Chinese language or turned it impure is a questions of debatable. As for communication, to achieve the best communicative effect, it is imperative to repeatedly use some new popular words. Additionally, the rise of social networking enables the visual culture gradually to be a part of the mainstream culture. Instead of the four-word phrase “我很高兴 (I m happy)”, now a symbol like “^_^” is more often used to express one’s delight. Culture depends on symbols increasingly. Besides, the existence of symbols facilitates the convey of communication. In Online Activities of Chinese net-users- “tell a story with emoji” game, netizens compete their capabilities to tell stories in emojis, without any language involved, which could be taken as a revolution of mode of expression.

Because of the existence of variation in any level of communication, there has been no such a thing can be called as pure Chinese culture, French culture and German culture and so on. Moreover, a new frontier emerges in cross-cultural problems. For example, is there typical structure between cross-cultural influencing factors? Is there deeper driving factor in intercultural communication? How people can solve the puzzle of cultural conflict? Under the background of multi-culture, communication research will inevitably involve with these issues. Thus, variation studies will focus on a variety of variation phenomena and the cultural factors behind the variation, which can definitely provide a discussion framework for the potential variability in the process of the communication.

As aforementioned, variation study is a new perspective of comparative literature studies. It studies the linguistic and cultural variation among the transmission of literary works, and probes the effective ways of variation in literary significance, theory and criticism between heterogeneous culture communication. Variation is not confined to comparative literature, and it also exists in the multi-cultural communication. Therefore, variation studies in comparative literature compares the "variation” phenomenon of language and culture, and information, as another form of literature, is also another medium for the communication of culture and language. So there is the possibility and feasibility for variation studies to refer to communication. 
The paper reinterprets communication from the perspective of variation studies by taking journalism and communication as an example.

\section{Case Study on Variations of International Journalism}

\subsection{Basic Features and Variations of International Journalism}

For a long time, the news reports are required to follow principles for being authentic and objective; the news practice and research trace back to seek the most original aspects of the stories. The demand to attract audience attention, which is the top consideration for certain reporters and journalists indicate the significance of an item of news might be intentionally or unintentionally "created” just for public concern, namely, the inevitability of news variation. Negatively speaking, public press is under cencorship in many countries. Actively speaking, the coping strategy is to endow news with new features though their own understanding as a compensation, which may deviate from the original texts, or deepen readers' understanding of the country of the original texts. Then, the analysis of news variation on the various levels can help to have a deeper understanding of the culture behind the news.

Variation studies advocates switching from the stage of "seeking the apparent affinities" to "seeking the difference” (Cao, 2013), that is, the exploration of different culture motivation under the surface of similarities. In the process of information transmission, the principle advocates focusing on the target language culture value orientation hidden behind the messages that communicators spread, communicators' culture background and the possibility if the disseminator and the receiver of news can understand each other under the circumstances of communication of the same contents.

Journalism and communication can also use variation studies theory because of the following several reasons: first of all, China's literature and journalism are near relations. Since modern times, the researches of literature and journalism have all taken off from the New Culture Movement, and have been sharing the common ground of criticism. Secondly, literature and journalism are consistent in research path and trend. Although journalism, as a discipline is slightly younger, they all introduce, translate, explore from and dialogue with their western counterparts since modern times. Now, both are integrating and reconstructing China's own path. Thus, by analyzing the deformation and torsion, variation even misunderstanding after the information exchange activities between different languages and different cultures, people can put forward new possibilities for cross-national, interlingual, intercultural and cross-civilization communication. This paper takes reports on China's “Belt and Road” as an example.

\subsection{The Analysis of News about China's Belt and Road Initiative}

The "Silk Road Economic Belt” and "Maritime Silk Road in the 21st Century” initiative were launched successively by Xi Jinping, the President of the People’s Republic of China in September and October 2013 respectively during his visits to central Asia and Southeast Asia. Then, “One Belt and One Road” strategic vision has continuously developed and improved. Besides, the National Development and Reform Commission, the Ministry of Foreign Affairs, and the Ministry of Commerce jointly issued the constructive vision and action files of “One Belt and One Road” Initiative. The files clearly and systematically described the historical background, co-construction principles, frame work thoughts, as well as cooperation focus, cooperation mechanism and operation methods of “One Belt and One Road” Initiative. Under the impact of many factors, such as thinking mode, differences of concept, and interest disagreement, there is variation in the news of "One Belt and One Road” Initiative in the process of communication. Western countries' misunderstanding of “One Belt and One Road” Initiative also has the inseparable relations with such variation during communication.

\subsubsection{Creative Treason in Cross-Language Variation}

Media discourse, as elite discourse, has the effect of guiding public opinion. Media information is the important foundation by which the public knows about the world. Variation will inevitably emerge when information is spread from one country to other countries, and such variation is often implied, fuzzy and potential. The variation firstly embodies in language variation. The concept “creative treason” first proposed by French scholar Robert Escarpit, is supposed to mean translation can be regarded as a kind of creative treason, giving works new look. While Xie Tianzhen, the Chinese scholar (Xie, 1999) even highlights that the translators deviate from the 
original texts according to the artistic creation representation in theory, but in fact, creativity and treason cannot be separated.

Apart from literature, media often determine the report contents according to their own concerns and the audiences' interests when reporting news, intentionally or unintentionally "Treason (betray)" the original messages. The process will accelerate the readers' absorption to the concept, and also mislead the readers. In the coverage of “One Belt and One Road” Initiative, the linguistic variation mainly took its forms as "mistranslation”, and negative words.

Firstly, the western media mentions more "economic belt” of "One Belt and One Road” Initiative, while rarely mentions "One Road”. Secondly, according to statistics, 25 published articles of the New York Times and Washington Post, mentioned only “One Belt and One Road” for 4 times, and "Silk Road Economic Belt” for 9 times. When the articles mention the strategic vision of "One Belt and One Road" Initiative, more of them use "new silk road" ("new silk road" was first proposed by the U.S. to solve the problem of Afghanistan). Thus, the author (Zheng, 2016) thinks it may make readers misunderstand, and that the American media used to apply its own discourse system. Thirdly, as for the use of words, most of the reports use words such as aggressive and ambitious, seldom use positive words like warm, and the between the lines implies a tone of concern.

Regardless of that the Creative Treason is intentional action or real incomprehension, the misunderstanding caused by the cross-linguistic variation is worth analyzing.

\subsubsection{Culture Filtering in Cross-Cultural Variation}

Western society misunderstands China’s “One Belt and One Road” Initiative mainly because they casually guess the motivation of such Initiative, namely, the misunderstanding of Chinese traditional culture. There are four kinds of misunderstanding in western society. For the most concerned kind of misunderstanding, western society considers China's “One Belt and One Road” Initiative as China’s version of Marshall Plan (Huang \& Chen 2015), thinks such Initiative reflects the strong intention that China aims to expand influence in the surrounding areas, and emphasizes the similarity of them in form (send the country's capital and technology to countries and regions which urgently need them). Besides, they match "Marshall Plan” (the measure of superpower hegemony, ideological confrontation and one country dominance) with China's “One Belt and One Road” Initiative, thinking such initiative is a kind of external expansion strategy of China, with the purpose of making China's excessive capacity "go out”, and it is foreign investment and development plan to the Association of South-east Asian Nations, central Asia and other regions, and a expansion strategy of China.

The view is actually a kind of Cultural Filtering which means that the receivers in the cross-cultural communication choose, transform, transplant and infiltrate the exchange information due to different cultural backgrounds and cultural traditions. In fact, western society only sees the similarities between "One Belt and One Road” Initiative and the Marshall plan in terms of economic development, but filters out the essence of "One Belt and One Road” Initiative (cooperation development, openness and inclusiveness, mutual benefit and winwin results). After filtering out these factors, the western society cannot understand the cultural factors because the culture of individualism prevails there. There are essential differences in their proposal background, main targets and basic carriers. Modern “One Belt and One Road” Initiative, as the continuation of the ancient Silk Road, inherits and carries forward the friendly cooperation, inclusiveness, coexistence and co-prosperity, and the spirit of seeking common ground while shelving the differences of the ancient Silk Road. Its most distinctive feature is openness and inclusiveness: open to all countries that seek development, never adopt "group politics" and confrontational "alliance", and emphasize the mutually beneficial and win-win "community of interests" and "community of common destiny". By contrast, the "Marshall Plan", the American initiative, aimed toconfront with the socialist camps, and pave the way for America’s world hegemony by means of western European countries. Therefore, taking the two as similar initiatives is a kind of misunderstanding with cultural filtering. However, many countries avoid and reject China's “One Belt and One Road” Initiative, so some people tend to mistakenly think it is similar with "Marshall Plan” (Ge \& Zhang, 2015). For this reason, Chinese scholars (like Liu, 2014; Cao et al., 2015; Ni \& Wang, 2015) are considering how to truly achieve the "Silk Road economic belt”.

\subsubsection{Domestic Appropriation}

According to historical evidence, there have been cultural misunderstanding and filtering due to the cultural differences between China and America for many times. Since the modern times, the U.S. media has often "im- 
agined" China. Chinese scholars divided the American media's misunderstanding of news of China after Kissinger's secret visit to China on June 9, 1971 into three stages: romanticizing in the 1970s, angel-like descriptions in the 1980s and the demonization in 1990s. With the time passing by, the understanding of the event has become objective.

Nowadays, relatively speaking, the opinion that western media reports is also the information from local observers, international scholars or governments officials, and it is much more objective than that 10 years ago from the macroscopic level. Although most of the American media still focuses on China's ethnic unrest, the South China Sea issue, etc., at the same time, "Misunderstand China” is also the key words of its media coverage of China among the observers, reporters, writers of publications such as the Seattle Globalist, the Diplomat Magazine, the Washington Post, The Wall Street Journal. The reflection brought by the news communication variation will make the U.S. have deeper understanding of the Oriental civilization, which can be seen from the change of the American media to China's misunderstanding.

\section{Conclusion: The Possible Function and Features of Communication Variation Theory}

This Paper tries to make attempts to propose Variation Theory of communication through decoding the reports on China's “One Belt and One Road” initiative by US Medias. There are the benefits of paying attention to variations in the communication. The study of variation in communication can promote cultural adaptation of heterogeneous culture, that is, the change of cultural characteristics when different cultural groups exchange, and form the interaction of idea transformation. People can liberate themselves from the shackles of the unconscious culture, and seek a dynamic culture in this way. This is advantage of Variation Theory of Communication.

Chinese communication studies lack linkup and inheritance, so communication studies has not formed systems and schools of thoughts in China. The number of research achievements has soared in recent years, but most of the researches still remain in the introducing level, and lack originality and theoretical depth. The emergence of Variation Theory may sort out a comparatively clear framework for the existing communication theory in China. Case study as this paper is, it needs more in-depth study and summary of variations to find out the ontology reference system and the complete system of variants, combing more theoretical information and empirical test.

\section{References}

Cao, S. Q. (2013). Variation Theory of Comparative Literature. Berlin: Springer-Verlag. http://dx.doi.org/10.1007/978-3-642-34277-6

Cao, X. S., Li, T., Yang, W.Y. et al. (2015). Accessibility and Urban Spatial Connections of Cities in the Silk Road Economic Belt Based on Land Transportation. Progress in Geography, 6, 657-664.

Chen, L. D. (2002). Opinions on the Study of Communication Science. Journal of International Communication, 2, 52-54.

Chen, X. M. (2005). The Significance of the Studies of "Western Marxism" in Contemporary China. Journal of Nanjing University (Philosophy, Humanities and Social Sciences), No. 2.

Chen, Y. K. (2015). A Comparative Study of Marx’s Theory of China and Western Marx Doctrine. Reform \& Opening, 9, 106-107.

Fokkema (2013). Foreword in Variation Theory of Comparative Literature (pp. v-vii). Berlin: Springer-Verlag.

Ge, J. X., \& Chen, P. (2015). Looking Back at the History of the Silk Road. Guang Ming Daily, 2015-07-09(011).

Hu, Y. Q. (2011). The Lost of the Communication Research’s Localization. Modern Communication, No. 4.

Huang, R. H., \& Chen, P. Y. (2015). Outside Misreading and Rational Reflection. The Belt and Road. Chinese Social Sciences Today, 2015-05-13(B02).

Li, J. Q. (2013). Re-Consideration on the Localization and Subjectivity of Journalism and Communication. Chinese Journal of Journalism \& Communication, 8, 171-173.

Liu, C. G. (2014). Development of Marine Partnership, Some Thoughts on Promoting the Construction of the Maritime Silk Road in Twenty-First Century. International Studies, 4, 1-8.

Liu, H. L. (2011). Two Dimensions of Localization of Communication Studies. Modern Communication, 9, 43-48.

Ni, M. M., \& Wang, M. C. (2015). The Realization Basis and Path Selection of Regional Monetary Cooperation in the Silk Road Economic Belt. Journal of Northwest University (Philosophy and Social Sciences Edition), 11, 119-124. 
Qin, H. Y. (1996). A Dialogue on Chinese Poetics and Western Poetics-An Interview with Jullien. Comparative Literature in China, No. 2, 77-87.

Said, E. (1983). Traveling Theory, the World, the Text, and the Critic, 1983. Cambridge: Harvard University Press.

Weisstein, U. (1973). Comparative Literature and Literary Theory: Survey and Introduction. Bloomington \&London: Indinan University Press.

Wu, F. (2014). State, Problems and Reflection on Journalism Study in Mainland China (1988-2011): Based on Evaluations of 516 Journalism Doctoral Dissertations. Journal of International Communication, 12, 98-113.

Xie, T. Z. (1999). Medio-Translatology. Shanghai: Shanghai Foreign Language Education Press.

Yan, S. D. (2000). On the "Cultural Context” and "Variant” as Well as the Occurrence of Literary Studies. Comparative literature in China, 3, 1-14.

Yue, D. Y. (1994). Cultural Difference and Cultural Misreading. Chinese Cultural Research, 4, 18.

Yue, D. Y., \& Le, P. (Eds.) (1995). Misreading in Searching the Dialogues between China and the West. Beijing: Peking University Press.

Zhang, F. (2016). The Necessity of the Integration of the Western Marx Doctrine and the Marx Doctrine in China. Intelligence, $1,226$.

Zheng, H., \& Li, J. (2016). “One Belt One Road” Strategy Constructed by US Media—Case Study on the Related Reports of the New York Times and the Washington Post. Journal of SUIBE, 23, 87-96.

Zheng, W. (2013). Brief Discussion on Relations between Sinicization, Modernization of Marxism and Western Marxism. Theory Horizon, 12, 5-8.

Submit or recommend next manuscript to SCIRP and we will provide best service for you:

Accepting pre-submission inquiries through Email, Facebook, Linkedin, Twitter, etc

A wide selection of journals (inclusive of 9 subjects, more than 200 journals)

Providing a 24-hour high-quality service

User-friendly online submission system

Fair and swift peer-review system

Efficient typesetting and proofreading procedure

Display of the result of downloads and visits, as well as the number of cited articles

Maximum dissemination of your research work

Submit your manuscript at: http://papersubmission.scirp.org/ 